\title{
Chemical Analysis of Thermoluminescent Colorless Topaz Crystal Using Laser-Induced Breakdown Spectroscopy
}

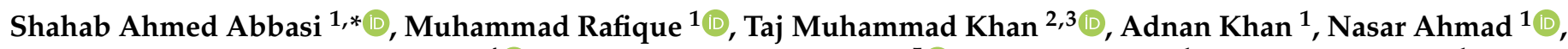 \\ Mohammad Rashed Iqbal Faruque ${ }^{4}\left(\mathbb{D}\right.$, Mayeen Uddin Khandaker ${ }^{5}\left({ }^{\circ}\right.$, Pervaiz Ahmad ${ }^{1}$ and Abdul Saboor ${ }^{1}$ \\ 1 Department of Physics, University of Azad Jammu and Kashmir, Muzaffarbad 13100, Pakistan; \\ mrafique@ajku.edu.pk (M.R.); adnan982@live.com (A.K.); nasar.ahmed@ajku.edu.pk (N.A.); \\ pervaiz.ahmad@ajku.edu.pk (P.A.); rajasaboor891@gmail.com (A.S.) \\ 2 National Institute of Lasers and Optronics (NILOP), P.O. Nilore, Islamabad 45650, Pakistan; khanta@tcd.ie \\ 3 School of Physics and CRANN, Trinity College Dublin, the University of Dublin, Dublin 2, Ireland \\ 4 Space Science Centre, Universiti Kebangsaan Malaysia, Bangi 43600, Selangor, Malaysia; rashed@ukm.edu.my \\ 5 Centre for Applied Physics and Radiation Technologies, School of Engineering and Technology, \\ Sunway University, Bandar Sunway 47500, Selangor, Malaysia; mayeenk@sunway.edu.my \\ * Correspondence: shahabphy12@gmail.com or shahab.ahmed@ajku.edu.pk; Tel.: +92-3025420455
}

\section{check for}

updates

Citation: Abbasi, S.A.; Rafique, M.; Khan, T.M.; Khan, A.; Ahmad, N.;

Faruque, M.R.I.; Khandaker, M.U.;

Ahmad, P.; Saboor, A. Chemical

Analysis of Thermoluminescent

Colorless Topaz Crystal Using

Laser-Induced Breakdown

Spectroscopy. Minerals 2021, 11, 367.

https://doi.org/10.3390/min11040367

Academic Editors: Samuel Moncayo

and Jorge Cáceres

Received: 2 December 2020

Accepted: 9 March 2021

Published: 31 March 2021

Publisher's Note: MDPI stays neutral with regard to jurisdictional claims in published maps and institutional affiliations.

Copyright: (c) 2021 by the authors. Licensee MDPI, Basel, Switzerland. This article is an open access article distributed under the terms and conditions of the Creative Commons Attribution (CC BY) license (https:/ / creativecommons.org/licenses/by/ $4.0 /)$.

\begin{abstract}
We present results of calibration-free laser-induced breakdown spectroscopy (CF-LIBS) and energy-dispersive X-ray (EDX) analysis of natural colorless topaz crystal of local Pakistani origin. Topaz plasma was produced in the ambient air using a nanosecond laser pulse of width $5 \mathrm{~ns}$ and wavelength $532 \mathrm{~nm}$. For the purpose of detection of maximum possible constituent elements within the Topaz sample, the laser fluences were varied, ranging $19.6-37.6 \mathrm{~J} \cdot \mathrm{cm}^{-2}$ and optical emission from the plasma was recorded within the spectral range of $250-870 \mathrm{~nm}$. The spectrum obtained has shown the presence of seven elements viz. $\mathrm{Al}, \mathrm{Si}, \mathrm{F}, \mathrm{O}, \mathrm{H}, \mathrm{Na}$ and $\mathrm{N}$. Results shows that the fluorine was detected at laser fluence higher than $35 \mathrm{~J} \cdot \mathrm{cm}^{-2}$ and plasma temperature of $>1 \mathrm{eV}$. Al and Si were found as the major compositional elements in topaz crystals. The ratios of concentrations of $\mathrm{Al}$ and $\mathrm{Si}$ were found as 1.55 and 1.59 estimated by CF-LIBS and EDX, respectively. Furthermore, no impurity was found in the investigated colorless topaz samples.
\end{abstract}

Keywords: CF-LIBS; energy-dispersive x-ray; topaz crystal; topaz plasma; laser fluence

\section{Introduction}

Topaz is a popular silicate mineral $\left(\mathrm{Al}_{2} \mathrm{SiO}_{4}(\mathrm{~F}, \mathrm{OH})_{2}\right)$ and is naturally found in a wide range of colors and colorless forms. Compared to other existing commercial materials, topaz is the hardest material, physio-chemically resistant to weathering, and possesses thermoluminescent characteristics [1]. Natural colorless topaz is largely utilized in jewelry, and the irradiation process is commonly employed to artificially induce colors in it [2]. In the jewelry industry, artificial methods are employed to induce colors in topaz, which include (i) irradiation with neutron, electrons and gamma rays followed by low-temperature annealing, (ii) colored metal oxide coating and (iii) heat treatment in different chemical atmospheres [3,4].

The thermoluminescent property makes topaz potentially an important candidate for its use as a thermoluminescent dosimeter (TLD) [5]. This property is exhibited by the insulators or semiconductors in which ionizing radiations are absorbed and remain trapped within the localized defects for a sufficiently long time. On thermal heating thermally heated, these materials emit the previously absorbed radiations and show a thermoluminescence character. The radiation trapping defect-sites in such crystals either could be due to the presence of extrinsic impurities or intrinsic defects such as lattice vacancies and interstitials [6]. High-energy TLD based on topaz crystals has been developed previously [7-11] The response of fabricated TLD strongly depends on the concentration of transition metals 
$(\mathrm{Ti}, \mathrm{V}, \mathrm{Cr}, \mathrm{Mn}, \mathrm{Fe}$, and $\mathrm{Cu}$ ), present as impurities in the topaz crystals or intrinsic defects, such as lattice vacancies and interstitials $[3,6]$. The concentration of these elemental impurities defines the performance of TLD; therefore, precise measurement of these impurities is crucial. The techniques of X-ray powder diffraction (XRD), energy-dispersive X-ray (EDX), $\mathrm{X}$-ray fluorescence (XRF), inductively coupled plasma mass spectrometry (ICP-MS), atomic absorption spectroscopy (AAS), and Raman spectroscopy are applied for trace element detections in a material.

Laser-induced breakdown spectroscopy (LIBS) is a powerful alternative analytical method having with few advantages over the conventional analytical techniques, such as simultaneous identification of elements, the requirement of nominal or no prior sample preparation, in situ analysis, the capability of analyzing liquid, gas and solid samples, fast response, identification of lighter elements, element identification in real time and low detection limit down to ppm or even better [12]. This method is straightforward, utilizing plasma from the probed sample, irradiated by a laser pulse of sufficient fluence. The characteristic spectral emission from the plasma gives elemental identification within the sample [13]. From the very first robust demonstration of the LIBS instrumentation on the surface of planet Mars [14], in order to carry out a qualitative analysis of minerals found on the Mars planet by Vadillo and Laserna in 1996, LIBS has had been established as a sensible route for qualitative and quantitative analysis for elemental and compositional analysis [15]. Later on, LIBS was used to investigate a variety of geo-materials [16-19]. This technique was also employed to identify emerald produced by different synthetic processes [20]. Similarly, several LIBS applications for terrestrial and extra-terrestrial geomaterials have been reported to date $[21,22]$.

LIBS utilizes calibration [23], calibration-free [24], and multivariate methodologies [25] to perform quantitative analysis of samples under investigation. In the calibration method, for the reference elements, calibration curves are drawn, and LIBS signals of different elements are compared with the corresponding curves. However, a running error due to the matrix effect and the appearance of several calibration curves in the case of multiple elements analysis makes this approach rather less attractive $[26,27]$. On the other hand, in the case of calibration-free analysis, both the intensity of the spectral lines and calculated plasma parameters, the temperature $\left(T_{e}\right)$ and density $\left(n_{e}\right)$, are used in the plasma model for quantification and in this procedure, uncertainties of matrix effect are ruled out $[28,29]$. In multivariate analysis, statistical and mathematical approaches are adopted for quantification and classification purposes [30].

Calibration-free laser-induced breakdown spectroscopy (CF-LIBS) has made possible to quantify the major and minor constituting elements of alexandrite crystal, and lighter element, like beryllium (Be), which were not easily detectable by several other techniques [31]. This technique is now frequently used to determine the number of trace elements and concentration of $\mathrm{Cu}$ and other elements in copper-rich minerals [32,33].

Topaz is technologically an impressive material for the scientific application, although the scientific community did not pay too much attention to explicitly explore it. Rossi et al. [34] studied colored topaz of Siberian origin using CF-LIBS and compared the results with electron microprobe analysis-wavelength dispersive spectrometry (EMPA-WDS) and laser ablation-inductively coupled plasma-mass spectrometry (LA-ICP-MS). For the major elements $\mathrm{Si}, \mathrm{Al}, \mathrm{Be}$ and $\mathrm{B}$, the results were in close agreement. However, in this study, fluorine, present in considerable amounts in all-natural topaz, was not detected. This may be because of the low laser pulse energy used in order to avoid surface damage. The detection of fluorine and its compounds is very important since they are being employed in fire extinguishers, pharmaceutical and agrochemical products, dental care products, polymers, etc. This gives an impression to develop a superior analytical method to provide a fast and precise quantitative detection of fluorine and its compounds for a thorough investigation. The direct determination of fluorine with the LIBS is a challenging task owing to the fact of its low excitation efficiency. Based on elemental and molecular band emission criteria, many research groups have attempted to detect and quantify fluorine 
using LIBS and chemometric techniques [35-38]. Contrary to the molecular band emission, LIBS analysis shows some strong spectral lines that may be employed for the detection of fluorine but with relatively weak emission intensity. in the spectral region between 623 and $780 \mathrm{~nm}$.

This work aims to investigate the existence of impurities, if any, in the colorless topaz crystal that may help in the future to establish the role of impurities in the TL character of topaz. Another objective is to detect fluorine in topaz with LIBS. This study can help in the development of topaz crystals as a TLD and understanding the mechanism of its TL response. In the present work, results of a spectroscopic study of natural colorless topaz crystal collected from the Skardu region of the northern part of Pakistan are presented. The CF-LIBS approach, together with optimized plasma parameters, has been employed to determine the elemental composition in natural topaz. Both qualitative and quantitative analysis was performed, and the results were compared with the EDX. The plasma parameters were studied to search for an optimum value suitable for the possible detection of fluorine.

\section{Materials and Methods}

\subsection{Geology of Sampling Area}

Colorless topaz crystals were collected from the Nyit Bruk mine located in the Shigar Valley, situated at a distance of around $32 \mathrm{~km}$ from the Skardu Gilgit Baltistan region of Pakistan. The valley is known for its diverse reserves of minerals and gemstones [39]. This area comprises of two tectonic plates: (i) Karakorum plate and (ii) the Kohistan- Ladakh island arc (KLIA) with the intervening northern or Shyok Suture Zone. These plates largely contain metasediments and meta igneous rocks along with pegmatitic dikes belonging to the Karakorum Metamorphic Complex [40,41].

\subsection{Sample Characteristics}

Ten pieces of natural colorless topaz crystal were collected from the Nyit Bruk mine. Samples were of smaller size with few millimeter dimensions. Topaz crystals were washed multiple times and then dried for the purpose of removing surface impurities. Since LIBS is a minimally destructive technique and removes mass of only micro Gram-per pulse, so just small spots were recorded on the surface of crystals after the laser ablation. A photograph of the topaz crystals used in this study is shown in Figure 1.

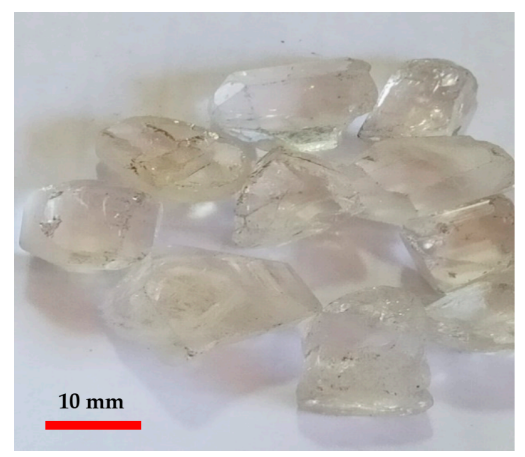

Figure 1. Photograph of the investigated natural colorless topaz crystals collected from Nyit Bruk mine Skardu.

\subsection{Experimental Arrangement}

Details of the experimental setup used for the current study can be found elsewhere [42]. Briefly, a high-power Q-switched Nd:YAG laser (Brilliant-Quantel, Lannion, France), pulse width $5 \mathrm{~ns}$ and wavelength $532 \mathrm{~nm}$, was used to produce a microplasma on the surface of the topaz crystal. The laser was capable of delivering maximum pulse energy of $500 \mathrm{~mJ}$ at $532 \mathrm{~nm}$ wavelength. The target was mounted on a rotatable stage to prevent crater formation and to provide a fresh surface to each laser shot. The spot size of the laser beam on the target surface was $0.10 \pm 0.01 \mathrm{~cm}$. The laser energy was 
varied from 154 to $295 \mathrm{~mJ}$ by changing the delay time of the Q-switch and measured by an energy meter (Nova-Quantel, Cournon-d'Auvergne, France). The laser radiation was focused using a convex lens with a focal length of $10 \mathrm{~cm}$. Plasma from a topaz target was produced for fluence values ranging from $19.6-37.6 \mathrm{~J} \cdot \mathrm{cm}^{-2}$. The corresponding laser intensity range was from $1.0 \times 10^{9}$ to $1.9 \times 10^{9} \mathrm{~W} / \mathrm{cm}^{2}$. Radiations from the topaz plasma were routed to a spectrometer through an optical fiber (high-OH, core dia. $600 \mu \mathrm{m}$ ) with a collimating lens $\left(0-45^{\circ}\right.$ field of view) positioned normal to the direction of the expansion of the plasma plume. A set of four spectrometers (Avantes, Apeldoorn, Holland) with a resolution of $0.06 \mathrm{~nm}$, covering the wavelength range of $250-870 \mathrm{~nm}$, was employed to record the spectra. Background signal was subtracted from original emission signal with the help of the AVASOFT 8.1.5 software The gate delay and gate width were set at 2 and $10 \mu \mathrm{s}$, respectively, from the onset of firing the laser shot. The schematic arrangement of the LIBS setup used in the current experiment is given in Figure 2.

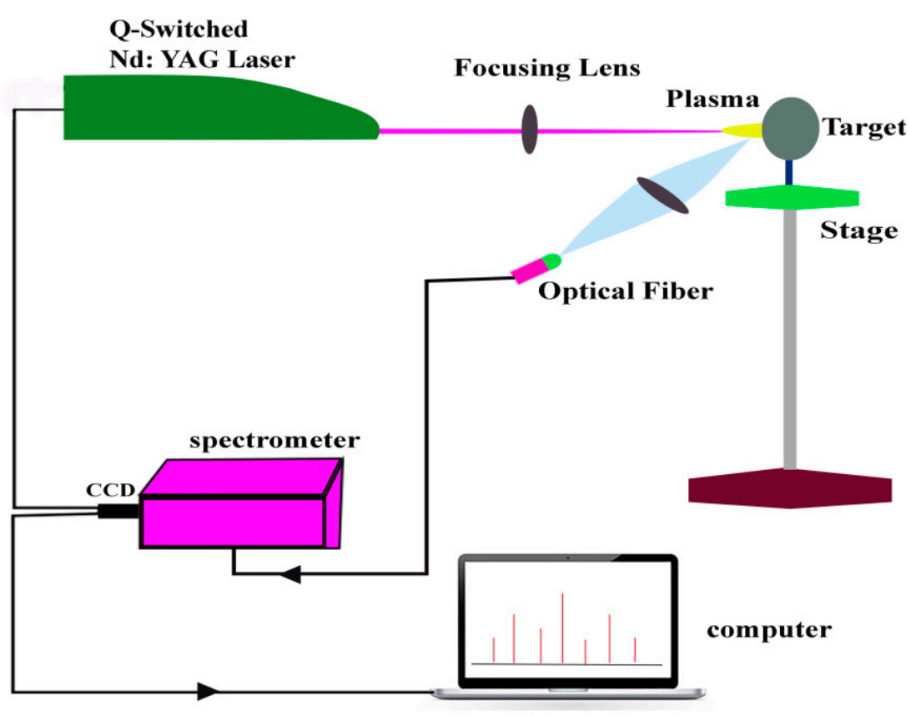

Figure 2. Schematic arrangement of the laser-induced breakdown spectroscopy (LIBS) detection system employed to perform the experiment.

\subsection{Theoretical Background}

CF-LIBS methodology [28] can be employed for quantitative analysis subject to the conditions that plasma is; (a) at local thermodynamic equilibrium (LTE), (b) optically thin, and (c) of stoichiometric ablation. The existence of LTE is an essential condition in the CF-LIBS method, and to accomplish this condition, atomic states should be populated and depopulated predominantly by electron collisions instead of radiation. This could happen if the electron number density $\left(n_{\mathrm{e}}\right)$ is sufficiently high. For a high collision rate, the required minimum value of $n_{e}$ is given by the McWhirter criterion [43]:

$$
\mathrm{n}_{\mathrm{e}} \geq 1.6 \times 10^{12}\left(\mathrm{~T}_{\mathrm{e}}\right)^{\frac{1}{2}}(\Delta E)^{3},
$$

where $T_{e}$ and $\Delta E$ are electron temperature, and the energy difference between the states expected to be in LTE, the McWhirter criterion for LTE in transient and inhomogeneous plasma is necessary, but not sufficient condition. In order to check the existence of LTE, Cristoforetti et al. [44] have suggested another criterion. According to them, in time duration of the order of atoms/ions relaxation time, the diffusion length $\left(D_{\lambda}\right)$ should be ten times less than the characteristic variation length (d) of electron number density and temperature in the plasma. Generally, the value of $d \approx f u /(d T(x) / d x)$ is considered as plasma diameter or fraction of it. In this expression, $T(x)$ is electron temperature at position $\mathrm{x}$ in 
plasma, and $d T(x) / d x$ shows the variation in temperature with position within the plasma. $D_{\lambda}(\mathrm{cm})$ can be estimated from the following expression:

$$
D_{\lambda}=1.4 \times 10^{12} \times\left(\frac{\left(k_{B} T\right)^{3 / 4}}{n_{e}}\right) \times\left(\frac{\Delta E}{M_{A} f_{12}<\bar{g}>}\right)^{1 / 2} \times \exp \left[\frac{\Delta E}{2 k_{B} T}\right]
$$

where $\Delta E(\mathrm{eV}), k_{B} T(\mathrm{eV}), n_{e}\left(\mathrm{~cm}^{-3}\right), M_{A}, f_{12}$, and $<\bar{g}>$ are upper-level energy, plasma temperature, electron number density, atomic mass, oscillator strength and gaunt factor, respectively.

To verify the condition of optically thin plasma, the intensity ratio method can be used given by the following expression [45]:

$$
\frac{I_{1}}{I_{2}}=\frac{\lambda_{2} A_{1} g_{1}}{\lambda_{1} A_{2} g_{2}} \exp \left[-\frac{E_{1}-E_{2}}{k_{B} T}\right]
$$

where $I_{1}$ and $I_{2}$ are experimentally measured intensities of the selected lines having wavelengths $\lambda_{1}$ and $\lambda_{2}$, whereas $A_{1}, A_{2}, g_{1}, g_{2}, E_{1}, E_{2}, k_{B}$ and $T$ are the transition probabilities, statistical weights and upper-level energies corresponding to lines 1 and 2, Boltzmann constant and temperature, respectively. The values of the upper energy level of a couple of selected lines could be either the same or very close to each other. The intensity ratio can be estimated with the help of Equation (3) by inserting the values of atomic parameters of selected pairs of atomic emission lines.

For quantification of multi-elemental materials, the plasma plume should represent the sample composition (stoichiometric ablation) and is possible for the laser intensity of $10^{9} \mathrm{~W} \cdot \mathrm{cm}^{-2}$ at the target surface [46]. Using a laser intensity $>10^{9} \mathrm{~W} \cdot \mathrm{cm}^{-2}$ can fairly justify the condition of stoichiometric ablation.

In the CF-LIBS technique, the atomic number density of neutral species can be found by using the following equation $[28,29]$ :

$$
N_{x}^{i}=\frac{I \lambda U_{x}^{i}\left(T_{e}\right)}{A_{b i} g_{b}}\left(4 \times 10^{14}\right) e^{\left(\frac{E_{b}}{K_{B} T_{e}}\right)}
$$

where, $\lambda, I, U_{x}^{i}(T), T_{e}, E_{b}, A_{b i}$ and $g_{b}$ are wavelength, intensity, the partition function of the neutral species, electron temperature, upper-level energy, transition probability and statistical weight, respectively. The Saha equation given by the expression below is used to calculate the density number of ionized species [47]:

$$
N_{x}^{i i}=2\left(N_{x}^{i}\right)\left(n_{e}{ }^{-1}\right)\left(6.04 \times 10^{21}\right)\left(T_{e}^{\frac{3}{2}}\right)\left(\frac{U_{x}^{i i}\left(T_{e}\right)}{U_{x}^{i}\left(T_{e}\right)}\right)\left(\frac{-\chi_{i}}{K_{B} T_{e}}\right),
$$

where, $N_{x}^{i}, U_{x}^{i i}\left(T_{e}\right), \chi_{i}$ are number density of neutral atoms, partition functions of ionized atoms at calculated plasma temperature, and ionization potential. Aggregate relative atomic number density of elements is obtained by adding neutral and ionized atomic number densities obtained from Equations (4) and (5):

$$
N_{x}=N_{x}^{i}+N_{x}^{i i}
$$

The weight of each element in the multi-elemental sample can be estimated by multiplying the relative atomic number density of each element with their corresponding atomic weight $\left(W A_{x} \times N_{x}\right)$ and weights so obtained were summed together $\left(S H_{x} W A_{x} \times N_{x}\right)$. Relative weight percentages of each element in the sample are then estimated as follows:

$$
\text { Weight percentage } x=\frac{W A_{x} \times N_{x}}{S H_{x}\left(W A_{x} \times N_{x}\right)} \times 100
$$




\section{Results and Discussion}

\subsection{Qualitative Analysis}

At low fluence values, only a few low-intensity lines of neutral atoms were present. In order to detect the emission lines of different elements present in the topaz, the laser fluence was optimized. These lines were recognized through a comparison of the experimentally observed wavelength lines to the available online database, managed by the National Institute of Science and Technology (NIST), USA [48]. At higher fluence $37.6 \mathrm{~J} \cdot \mathrm{cm}^{-2}$, the maximum number of emission lines were present in the spectra. To clearly understand and classify the emission lines, the spectrum was broken into smaller parts, which are displayed in Figure 3.
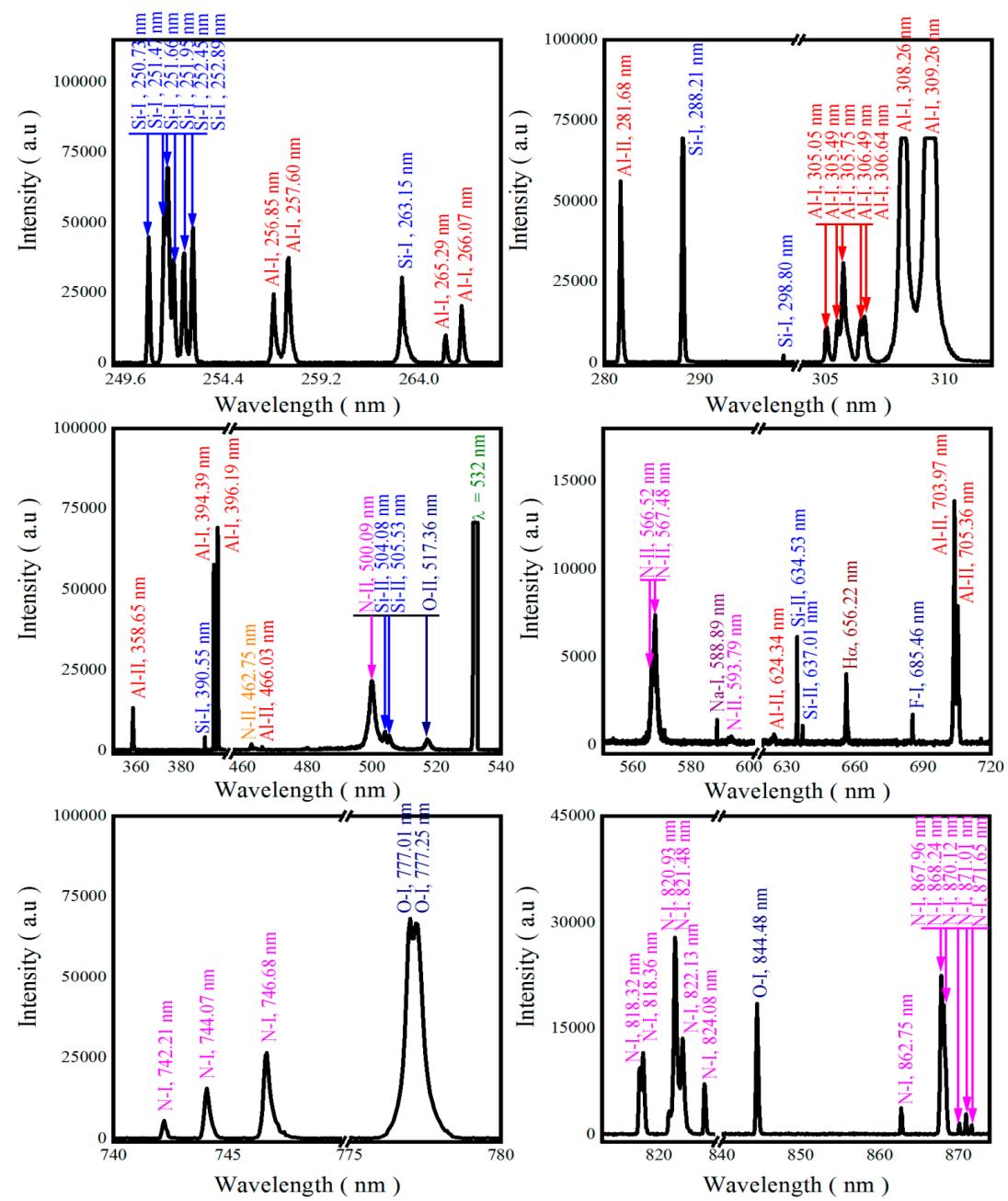

Figure 3. Optical emission spectra from laser-induced plasma of natural colorless topaz crystal obtained in the spectral range of $(250-870) \mathrm{nm}$ at a laser fluence of $37.6 \mathrm{~J} \cdot \mathrm{cm}^{-2}$.

The neutral atoms lines are represented by I and those of ionized atoms by II. The lines identified show the presence of aluminum, silicon, oxygen, nitrogen, hydrogen, sodium and fluorine in the topaz crystals. The spectrum is comprised of ten Si-I and four Si-II lines, thirteen Al-I and six Al-II lines, fifteen N-I and five N-II lines, three O-I and a single line of each H, F-I and Na-I, and gives a clear manifestation of the chemical composition of topaz. For the laser ablation in the ambient air, there is a great possibility for nitrogen in the spectra, as observed previously using the same spectrometer [49]. The possible reasons for the Na line in the spectra at a higher laser fluence value of $37.6 \mathrm{~J} \cdot \mathrm{cm}^{-2}$ could be either due to; (i) small impurities in topaz crystals or (ii) contamination from human touch and experimental atmosphere. 
Fluorine detection with the LIBS in solid samples is a challenging task. The strongest and the most persistent emission lines of neutral fluorine within the spectral range of 200-900 nm are laying at around 685 and $703 \mathrm{~nm}$ [36]. The upper energy levels of transition for these lines are at 14.5 and $14.7 \mathrm{eV}$, respectively. To be able to observe the fluorine emission line, we worked with the plasma produced at a higher laser fluence beyond $33.1 \mathrm{~J} \cdot \mathrm{cm}^{-2}$. The emission line of neutral fluorine at $685.46 \mathrm{~nm}$ was appeared at $35.4 \mathrm{~J} \cdot \mathrm{cm}^{-2}$, showing an increase in intensity as fluence reaches $37.6 \mathrm{~J} \cdot \mathrm{cm}^{-2}$ (see Figure 4).

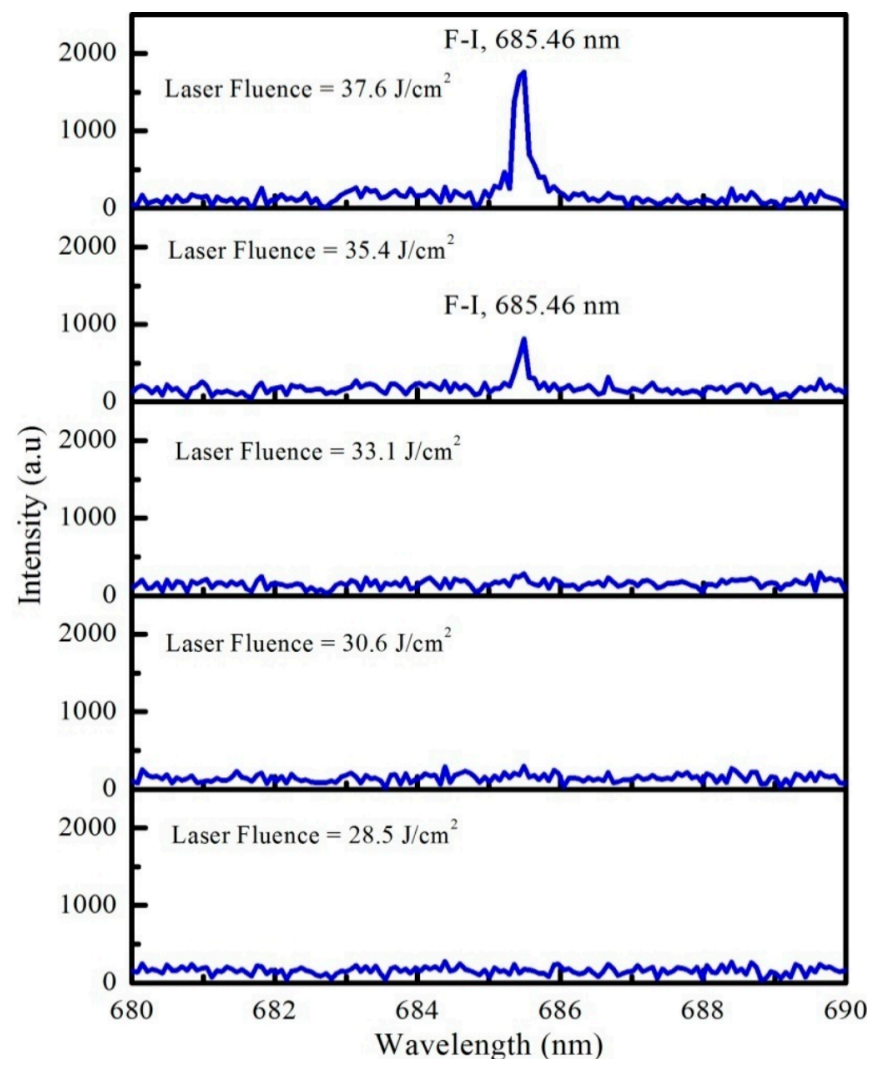

Figure 4. Emission line spectra in the region of interest showing the appearance of the F-I line at $685.46 \mathrm{~nm}$ from topaz plasma induced at fluence values in the range of $28.5-37.5 \mathrm{~J} \cdot \mathrm{cm}^{-2}$.

It is noteworthy to mention that the strong emission line at $703.97 \mathrm{~nm}$ could not be assigned to F-I because this line was initially present at low fluence, and it resembles more closely the Al-II line.

Further, to observe the effects of plasma parameters on emission lines, both electron temperature $\left(\mathrm{T}_{\mathrm{e}}\right)$ and electron number density $\left(\mathrm{n}_{\mathrm{e}}\right)$ were determined. The emission of the F-I line around $685.46 \mathrm{~nm}$ became possible for $\mathrm{T}_{\mathrm{e}} \geq 11,975 \mathrm{~K}$ and $\mathrm{n}_{\mathrm{e}} \geq 2.74 \times 10^{17} \mathrm{~cm}^{-3}$ suggesting some threshold or minimum values of plasma parameters to possibly detect F-I lines. However, these values are annexed to this particular experiment and may vary otherwise.

\subsection{Quantitative Analysis}

For quantitative analysis, the CF-LIBS method [28] was used by strictly considering the conditions that plasma was; (a) at LTE, (b) optically thin, and (c) of stoichiometric ablation. To verify the validity of these conditions and subsequently use CF-LIBS methodology to determine the elemental concentration, the measurement of plasma parameters is described below. 


\subsubsection{Electron Temperature}

Boltzmann plot method was employed to make an estimation of the electron temperature using the expression [50]:

$$
\ln \left(\frac{I_{\lambda}^{b a} \lambda}{h c A_{b a} g_{b a}}\right)=\ln \left(\frac{N(t)}{U(t)}\right)-\frac{E_{b a}}{K T_{e}}
$$

where $I_{\lambda}^{b a}, \lambda(\mathrm{nm}), A_{b a}\left(\mathrm{~s}^{-1}\right), g_{b a}, \mathrm{~N}(\mathrm{t}), U\left(T_{e}\right), E(\mathrm{eV})$ and $\mathrm{T}_{\mathrm{e}}$ are the integrated line intensity, wavelength, transition probability, statistical weight of upper-level (b), total number density, partition function, the energy of the upper-level, Boltzmann constant, and electron temperature, respectively. By plotting $\ln \left(\frac{I \lambda}{h c A g}\right)$ against the upper-level energy E, the electron temperature was calculated from the slope $-1 / \mathrm{kT}_{\mathrm{e}}$ with a propagation error of about $\pm 5 \%$. The error is mainly due to uncertainties of transition probabilities and integrated intensities of the spectral lines. For the Boltzmann plot, selected Al-I lines and their relevant spectroscopic parameters are listed in Table 1.

Table 1. Spectroscopic parameters of Al-I lines used to draw the Boltzmann plot.

\begin{tabular}{|c|c|c|c|c|}
\hline Element & Wavelength $\lambda(\mathrm{nm})$ & $\begin{array}{c}\text { Transition Probability } \\
\text { A }\left(\mathrm{s}^{-1}\right)\end{array}$ & Statistical Weight (k) & $\begin{array}{c}\text { Upper-Level Energy } E_{k} \\
\left(\mathrm{~cm}^{-1}\right)\end{array}$ \\
\hline Al-I & 256.85 & $1.92 \times 10^{7}$ & 4 & $38,929.41$ \\
\hline Al-I & 257.60 & $3.60 \times 10^{7}$ & 6 & $38,933.97$ \\
\hline Al-I & 265.29 & $1.42 \times 10^{7}$ & 2 & $37,689.41$ \\
\hline Al-I & 266.07 & $2.84 \times 10^{7}$ & 2 & $37,689.41$ \\
\hline Al-I & 308.26 & $5.87 \times 10^{7}$ & 4 & $32,435.45$ \\
\hline Al-I & 309.26 & $7.29 \times 10^{7}$ & 6 & $32,436.80$ \\
\hline
\end{tabular}

The quantitative results are affected by the uncertainties in line intensities and broadening arising from self-absorption in the plasma. Intensities of identified lines of different elements in the spectrum have been corrected using the method described by Sun et al. [51] for the purpose of minimizing uncertainties and self-absorption. An internal reference line with negligible self-absorption of each species in the spectrum was selected, and the self-absorption coefficient for the reference line $f_{\lambda R}$ was assumed to be unity. A criterion for the selection of a reference line is to select the line with low transition probability $A_{b a}$ or a high upper-level energy $E_{b}$. Al-I line at $265.29 \mathrm{~nm}$ was selected as the reference line, and the self-absorption coefficient $f_{\lambda}$ of other spectral lines was calculated by using the following expression:

$$
f_{\lambda}=\frac{I_{\lambda}^{b a} A_{m n} g_{m n}}{I_{\lambda_{R}}^{m n} A_{b a} g_{b a}} \exp \left[-\frac{E_{m}-E_{b}}{k_{B} T_{e}}\right]
$$

where $\lambda_{R}, I_{\lambda_{R}}^{m n}, A_{m n}$, and $g_{m n}$ are the wavelength, spectral line intensity, transition probability, and statistical weight of standard reference line related to the transition between energy levels $\mathrm{m}$ and $\mathrm{n}$, while $I_{\lambda}^{b a}, A_{b a}$ and $g_{b a}$ are the spectral line intensity, transition probability and statistical weight of other spectral lines related to the transition between energy levels $a$ and $b . E_{m}$ and $E_{b}$ are the upper-level energies of the internal reference line and other spectral lines, respectively and $T_{e}$ is the electron temperature previously obtained from the Boltzmann plot without correction for self-absorption. Intensity correction was done by dividing the experimentally observed intensity of a line by the self-absorption coefficient $f_{\lambda}$ as follows:

$$
I_{\lambda_{\text {corrected }}^{b a}}^{b}=\frac{I_{\lambda}^{b a}}{f_{\lambda}}
$$


After self-absorption correction, the intensities values were used in Equation (8), and the Boltzmann plot was re-plotted. $T_{e}$ was obtained from the slope of the Boltzmann plot, and the process was repeated until a negligible difference in the temperature reached up, and a best-fit to the line was obtained. The Boltzmann plots for $37.6 \mathrm{~J} \cdot \mathrm{cm}^{-2}$ without and with self-absorption correction are shown in Figure $5 \mathrm{a}, \mathrm{b}$, respectively. With self-absorption correction, an excellent linear fit was obtained with an $\mathrm{R}^{2}$ value of $99.9 \%$, and the $T_{e}$ values were $10,724 \pm 536 \mathrm{~K}$ and $12,660 \pm 633 \mathrm{~K}$ without and with correction of self-absorption, respectively. The correspondence $T_{e}$ plot with self-absorption correction for the different fluence values is shown in Figure $5 \mathrm{c}$. As expected, $\mathrm{T}_{\mathrm{e}}$ values were increased by increasing the laser fluence.
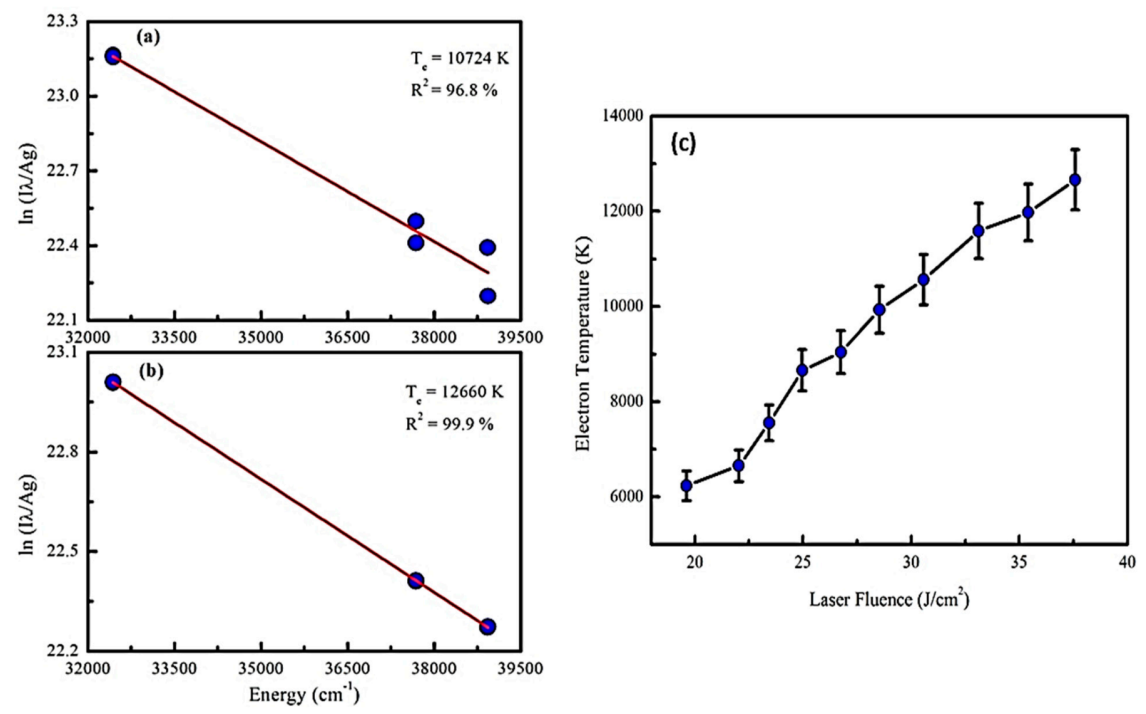

Figure 5. Boltzmann plots drawn using Al-I lines at laser fluence $37.6 \mathrm{~J} \cdot \mathrm{cm}^{-2}$ : (a) without and (b) with correction for self-absorption in the intensity of the spectral lines (c) variation of electron temperature with the laser fluence ranging $(19.6-37.6) \mathrm{J} \cdot \mathrm{cm}^{-2}$.

\subsubsection{Electron Number Density}

Stark broadened line profiles of well isolated spectral lines were used to determine $n_{e}$ using the following simplified expression [43,52]:

$$
n_{e}=\frac{1}{2} \Delta \lambda_{\frac{1}{2}} \times 10^{16}
$$

where $\omega$ is Stark parameter, and its value was taken from the literature [53] $\Delta \lambda_{\frac{1}{2}}$ denotes full width at half maximum (FWHM) of Stark broadened line and its value was taken from Lorentzian fit made to the selected lines and a representative of Al-I line at $396.17 \mathrm{~nm}$, is shown in Figure 6a. The value was corrected for instrumental width of $0.06 \mathrm{~nm}$. The average value of $\mathrm{n}_{\mathrm{e}}$ was obtained using the lines of Al-I at 257.60 and $396.17 \mathrm{~nm}$, Si-I at $288.21 \mathrm{~nm}$ and N-I at $746.68 \mathrm{~nm}$. The dependence of $\mathrm{n}_{\mathrm{e}}$ is shown on laser fluence is given in Figure $6 \mathrm{~b}$. The increase in $\mathrm{n}_{\mathrm{e}}$ with laser fluence could be due to the coupling of more energy to the surface. Energy coupling leads to plasma heating and increases ionization, well consistent with the previous observation [54]. The average value of $n_{e}$ calculated for the laser fluence $37.6 \mathrm{~J} \cdot \mathrm{cm}^{-2}$ was $3.08 \times 10^{17} \mathrm{~cm}^{-3}$.

\subsubsection{Local Thermodynamic Equilibrium (LTE)}

LTE condition was verified using the McWhirter criterion given in Equation (1) [43]. For the Si-I line at $288.20 \mathrm{~nm}$, the energy difference between states is $\Delta \mathrm{E}=4.3 \mathrm{eV}$. McWhirter criterion suggests that for plasma temperature of $12,660 \mathrm{~K}$, a value of $n_{e}\left(\mathrm{~cm}^{-3}\right) \geq 1.4 \times 10^{16}$ would be required for LTE to existing. The McWhirter criterion was also verified for various 
spectral lines of identified minor and major elements in emission spectra and the results indicated the existence of LTE condition.

In order to check the existence of LTE, another criterion suggested by Cristoforetti et al. [44] was also verified. For the calculation of diffusion length $\left(D_{\lambda}\right)$, values of $f_{12}$, and $\langle\bar{g}\rangle$ were obtained from the NIST database and Cristoforetti et al., respectively [44,48]. For the selected emission lines of $\mathrm{Si}$ and $\mathrm{Al}$, the calculated values of $D_{\lambda}$ given in Table 2, were found to be 10 times less than the assumed characteristic variation length (d) of $2 \mathrm{~mm}$. This result further validates the LTE assumption.
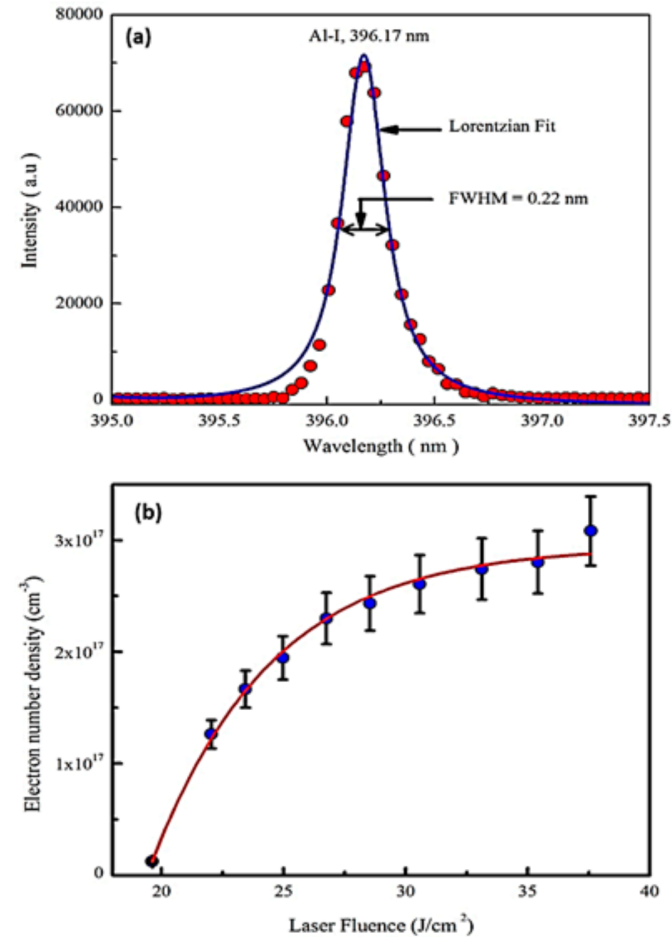

Figure 6. (a) Stark broadened line profile of Al-I line at $396.17 \mathrm{~nm}$ recorded for laser fluence of $37.6 \mathrm{~J} \cdot \mathrm{cm}^{-2}(\mathbf{b})$ Electron number density as a function of laser fluence.

Table 2. Spectroscopic parameters of the selected emission lines and calculated values of $\mathrm{D}_{\lambda}$ for the validation of local thermodynamic equilibrium (LTE) condition.

\begin{tabular}{|c|c|c|c|c|c|c|c|}
\hline Element & Wavelength (nm) & Oscillator Strength $f_{12}$ & $\mathbf{M}_{\mathrm{A}}$ & $\Delta E(\mathrm{eV})$ & $<\bar{g}>$ & $\mathrm{D}_{\lambda}(\mathrm{mm})$ & $10 \mathrm{D}_{\lambda}(\mathrm{mm})$ \\
\hline $\mathrm{Si}$ & 288.20 & $1.62 \times 10^{-1}$ & 28.08 & 4.30 & $\approx 0.1$ & 0.001 & 0.01 \\
\hline $\mathrm{Al}$ & 396.19 & $1.16 \times 10^{-1}$ & 26.98 & 3.12 & $\approx 0.1$ & 0.0006 & 0.006 \\
\hline
\end{tabular}

\subsubsection{Optically Thin Plasma}

The intensity ratio method was used to verify the condition of optically thin plasma [45]. The two pair lines of Si-I at 250.73 and 251.65, 251.47 and $251.97 \mathrm{~nm}$, and three pairs of Al-I lines at 256.86 and $257.80 \mathrm{~nm}, 265.32$ and $266.10 \mathrm{~nm}, 308.37$ and $309.43 \mathrm{~nm}$ were used. The intensity ratios calculated experimentally and theoretically using Equation (3) were 0.38 and $0.33,1.31$ and 1.35 for two pairs of Si-I lines and 0.41 and $0.36,0.44$ and $0.5,0.57$ and 0.56 for three pairs of Al-I lines, respectively. Both theoretical and experimental intensity ratios are close enough to consider that plasma was optically thin, and the self-absorption was not overwhelming. After correcting the line intensities with the help of the aforementioned self-absorption correction method using Equations (9) and (10), intensity ratios were again calculated, and results showed almost complete agreement between theoretical 
and experimental intensity ratio values. This implies that the effect of self-absorption was reduced to a minimum value.

\subsubsection{CF-LIBS Analysis}

To quantify the elements identified in the topaz sample by CF-LIBS, the selection of emission lines was made according to the selection criteria mentioned in [28,29]. For measurement of Si concentration, Si-I lines at 250.73, 251.66, 251.97, 252.45, 252.89, 263.15, 288.21, 298.78 and $390.54 \mathrm{~nm}$ were selected, and for measurement of Al concentration, the Al-I lines at 257.60, 266.07 and $396.19 \mathrm{~nm}$ were used. The relevant spectroscopic parameters of these lines are listed in Table 3.

Table 3. Spectroscopic parameters of selected lines of Si-I and Al-I used for quantitative analysis of topaz crystals using the CF-LIBS method.

\begin{tabular}{|c|c|c|c|c|}
\hline Element & $\begin{array}{c}\text { Wavelength } \\
\lambda(\mathrm{nm})\end{array}$ & $\begin{array}{c}\text { Transition Probability } \\
\text { A }\left(\mathrm{s}^{-1}\right)\end{array}$ & $\begin{array}{l}\text { Statistical } \\
\text { Weight (k) }\end{array}$ & $\begin{array}{c}\text { Upper-Level Energy } \\
\mathrm{E}_{\mathrm{k}}\left(\mathrm{cm}^{-1}\right)\end{array}$ \\
\hline Si-I & 250.73 & $5.47 \times 10^{7}$ & 5 & $39,955.05$ \\
\hline Si-I & 251.66 & $1.68 \times 10^{8}$ & 5 & $39,955.05$ \\
\hline Si-I & 251.97 & $5.49 \times 10^{7}$ & 3 & $39,760.28$ \\
\hline Si-I & 252.45 & $2.22 \times 10^{8}$ & 1 & $39,683.16$ \\
\hline Si-I & 252.89 & $9.04 \times 10^{7}$ & 3 & $39,760.28$ \\
\hline Si-I & 263.15 & $1.06 \times 10^{8}$ & 3 & $53,387.33$ \\
\hline Si-I & 288.21 & $2.17 \times 10^{8}$ & 3 & $40,991.88$ \\
\hline Si-I & 298.78 & $2.66 \times 10^{6}$ & 3 & $39,760.28$ \\
\hline Si-I & 390.55 & $1.33 \times 10^{7}$ & 3 & $40,991.88$ \\
\hline Al-I & 257.60 & $3.60 \times 10^{7}$ & 6 & $38,933.97$ \\
\hline Al-I & 266.07 & $2.84 \times 10^{7}$ & 2 & $37,689.41$ \\
\hline Al-I & 396.19 & $9.85 \times 10^{7}$ & 2 & $25,347.76$ \\
\hline
\end{tabular}

The number density of neutral and singly ionized atoms of Si and Al was calculated using Equations (4) and (5), respectively and the total number density of each species was obtained by summing the number density of neutral and singly ionized atoms of both of these elements. Calculated values of the number densities for each selected line of Si-I and Al-I are given in Table 4. The average number density of both the species was taken for calculating their concentration in the sample using Equation (7).

Table 4. Atomic number densities of neutral and ionized species of topaz crystals at a plasma temperature of $12,660 \pm 633 \mathrm{~K}$.

\begin{tabular}{lcccc}
\hline Element & $\begin{array}{c}\text { Wavelength } \\
\lambda(\mathbf{n m})\end{array}$ & $\begin{array}{c}\text { Number Density of Neutral } \\
\text { Species } \\
N_{x}^{i}\left(\mathbf{c m}^{-3}\right)\end{array}$ & $\begin{array}{c}\text { Number Density of Ionized } \\
\text { Species } \\
N_{x}^{i i}\left(\mathbf{c m}^{-3}\right)\end{array}$ & $\begin{array}{c}\text { Sum of Number Densities of } \\
\text { Neutral and Ionized Species } \\
\mathbf{N}_{x}\left(\mathbf{c m}^{-3}\right)\end{array}$ \\
\hline Si-I & 250.73 & $2.29 \times 10^{16}$ & $3.67 \times 10^{15}$ & $2.66 \times 10^{16}$ \\
\hline Si-I & 251.66 & $1.89 \times 10^{16}$ & $3.03 \times 10^{15}$ & $2.19 \times 10^{16}$ \\
\hline Si-I & 251.97 & $2.75 \times 10^{16}$ & $4.40 \times 10^{15}$ & $3.19 \times 10^{16}$ \\
\hline Si-I & 252.45 & $2.79 \times 10^{16}$ & $4.47 \times 10^{15}$ & $3.24 \times 10^{16}$ \\
\hline Si-I & 252.89 & $2.87 \times 10^{16}$ & $4.59 \times 10^{15}$ & $3.32 \times 10^{16}$ \\
\hline Si-I & 263.15 & $1.12 \times 10^{17}$ & $1.79 \times 10^{16}$ & $1.30 \times 10^{17}$ \\
\hline Si-I & 288.21 & $4.47 \times 10^{16}$ & $7.16 \times 10^{15}$ & $5.18 \times 10^{16}$ \\
\hline Si-I & 298.78 & $2.04 \times 10^{16}$ & $3.27 \times 10^{15}$ & $2.37 \times 10^{16}$ \\
\hline Si-I & 390.55 & $1.28 \times 10^{16}$ & $2.06 \times 10^{15}$ & $1.49 \times 10^{16}$ \\
\hline Al-I & 257.60 & $5.63 \times 10^{16}$ & $4.65 \times 10^{15}$ & $6.09 \times 10^{16}$ \\
\hline Al-I & 266.07 & $7.77 \times 10^{16}$ & $6.42 \times 10^{15}$ & $8.41 \times 10^{16}$ \\
\hline Al-I & 396.19 & $4.77 \times 10^{16}$ & $3.94 \times 10^{15}$ & $5.17 \times 10^{16}$ \\
\hline
\end{tabular}


Oxygen is a constituent of topaz, but hard to determine its actual amount due to performing experiments in the ambient air. Similarly, the quantification of $\mathrm{Na}$ was also not performed as the detected line was a resonant line and is not allowed to use by the selection criteria. Only a single detected line of F was also not appropriate for quantitative analysis owing to high uncertainty associated with the determination of the concentration of a single line. Moreover, the upper energy level at $685.45 \mathrm{~nm}$ line of F-I is $14.5 \mathrm{eV}$, which is much higher than the upper-level energies of Al-I lines from 4.95 to $6.62 \mathrm{eV}$, and Si-I lines from 3.14 to $4.83 \mathrm{eV}$, thus makes it unsuitable for quantitative analysis. In the natural colorless topaz sample, the concentration of $\mathrm{Al}$ and $\mathrm{Si}$ in terms of weight percentage $(\mathrm{Wt}$ $\%$ ) was found as 60.81 and $39.18 \%$, respectively.

EDX analysis was also performed to make a comparison, and the EDX spectrum is given in Figure 7. The presence of $\mathrm{Al}, \mathrm{Si}, \mathrm{O}$ and $\mathrm{F}$ in the colorless topaz crystal was verified by the EDX, while N, H and Na were not detected in the sample. EDX analysis showed the concentration of $\mathrm{Al}, \mathrm{Si}, \mathrm{O}$ and $\mathrm{F}$ as $37.27,23.41,28.94$ and $10.38 \%$ by weight percentage, as presented in Table 5. The concentrations of $\mathrm{N}$ and $\mathrm{O}$ were not calculated because EDX analysis showed no $\mathrm{N}$ in the topaz sample, and its presence in the LIBS spectrum arises from the ambient air. Since all these four elements were not quantified by CF-LIBS, so it is hard to draw a comparison of elemental concentration of these elements; however, the ratio of concentrations of $\mathrm{Al}$ and $\mathrm{Si}$ were calculated. The ratio of $\mathrm{Al} / \mathrm{Si}$ for CF-LIBS and EDX was found to be 1.55 and 1.59 , respectively. Results obtained by these two techniques show a reasonably good agreement and are summarized in Table 5.

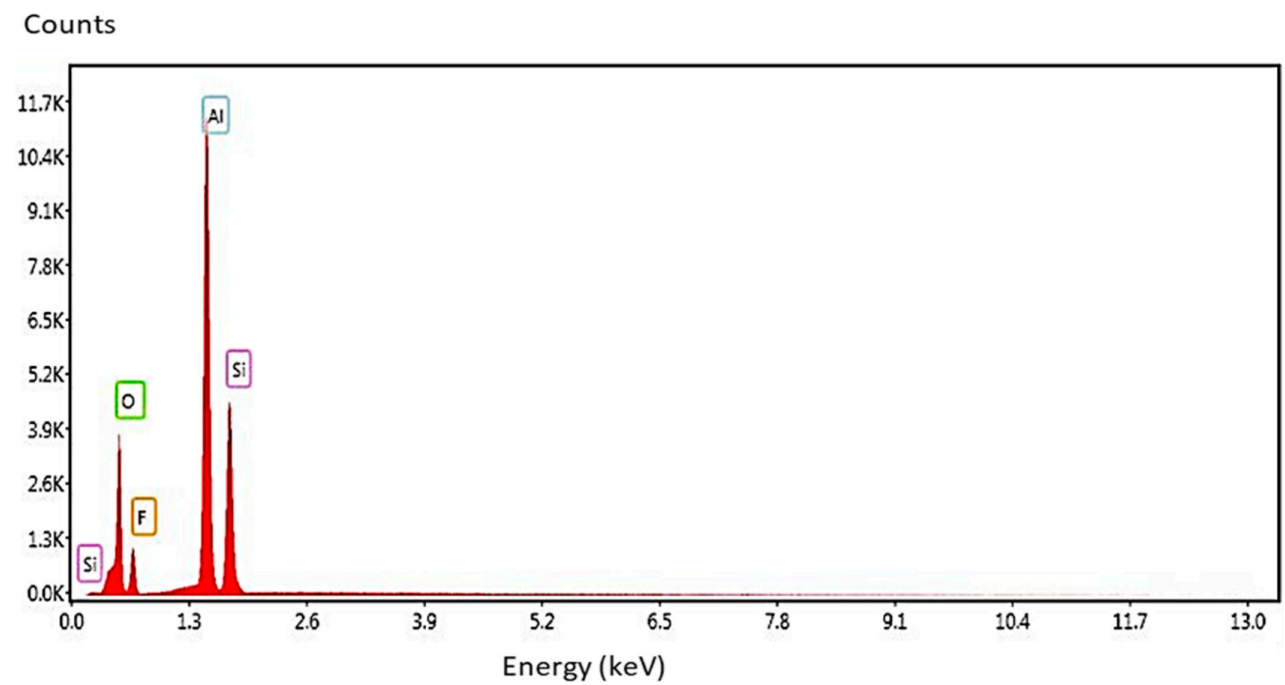

Figure 7. Energy dispersive X-ray (EDX) spectrum of topaz crystals.

Table 5. Elemental compositions of different elements present in topaz crystals measured by CF-LIBS and EDX techniques.

\begin{tabular}{|c|c|c|c|c|c|c|c|}
\hline Element & $\begin{array}{c}\text { Formula } \\
(\mathrm{Wt} . \%) \text { [55] }\end{array}$ & $\begin{array}{l}\text { CF-LIBS } \\
(\text { Wt. \%) }\end{array}$ & $\begin{array}{c}\text { EDX } \\
(\mathrm{Wt} . \%)\end{array}$ & $\begin{array}{c}\mathrm{Al} / \mathrm{Si} \\
\text { (Formula) }\end{array}$ & $\begin{array}{c}\mathrm{Al} / \mathrm{Si} \\
\text { (CF-LIBS) }\end{array}$ & Al/Si (EDX) & Relative Error \\
\hline $\mathrm{Al}$ & 29.61 & 60.81 & 37.27 & \multirow{7}{*}{1.92} & \multirow{7}{*}{1.55} & \multirow{7}{*}{1.59} & \multirow{7}{*}{ \pm 2.52} \\
\hline $\mathrm{Si}$ & 15.41 & 39.18 & 23.41 & & & & \\
\hline $\mathrm{O}$ & 43.02 & - & 28.94 & & & & \\
\hline $\mathrm{F}$ & 11.47 & - & 10.38 & & & & \\
\hline $\mathrm{Na}$ & - & - & - & & & & \\
\hline $\mathrm{N}$ & - & - & - & & & & \\
\hline $\mathrm{H}$ & 0.50 & - & - & & & & \\
\hline
\end{tabular}




\section{Discussion}

Qualitative results obtained with the help of the LIBS have shown the presence of all the elements in the chemical formula of topaz, $\mathrm{Al}_{2} \mathrm{SiO}_{4}(\mathrm{~F}, \mathrm{OH})_{2}$, and additionally, $\mathrm{N}$ and $\mathrm{Na}$ were also detected. The absence of $\mathrm{N}$ and $\mathrm{Na}$ in the EDX spectrum has confirmed that the presence of $\mathrm{N}$ lines in the LIBS spectrum was due to air, and the Na line could possibly be due to surface contamination. These results prove the chemical purity of colorless topaz crystal. Colorless topaz crystal of Pakistani origin was developed as a TL dosimeter, and its radiation monitoring efficacy and detection efficiency were found comparable to a high-energy TL dosimeter, such as TLD-100 [7,8]. Similarly, natural colorless topaz crystals from Brazil have shown better sensitivity to ultra-violet and gamma radiations compared to colored topaz crystals $[6,56]$. The current study suggests that the TL response of colorless topaz crystals might be due to intrinsic defects rather than the presence of impurities $[3,11]$. However, we cannot rule out completely the presence of impurities in concentrations less than the detection limits of the LIBS and EDX.

Quantitative results described in Table 4 give the realization that colorless topaz crystal is free from impurity except for environmental contamination. In a CF-LIBS study made by Rossi et al. [30], the pale yellow and pale green topaz has shown the presence of Fe and $\mathrm{Mn}$, which are believed to be the reason for the colors of topaz. CF-LIBS technique could quantify only two major elements of topaz, namely $\mathrm{Al}$ and $\mathrm{Si}$, while the EDX analysis has quantified all the elements present in the chemical formula of topaz except hydrogen. Hydrogen cannot be detected with the help of the EDX due to the limitation of this technique. The ratio of weight percentage of $\mathrm{Al}$ to $\mathrm{Si}$ as measured by CF-LIBS and EDX technique was 1.55 and 1.59, respectively, as compared to 1.92 according to the chemical formula of pure topaz [55].

This study strongly validates the effectiveness of the LIBS to detect main constituents in the sample and other lighter elements, such as hydrogen. For quantitative analysis, the CF-LIBS technique has few limitations, such as unavailability of the spectral lines of some elements in the multi-elemental sample and low sampling mass (ablated mass per laser shot $\approx$ nanogram). The capability of CF-LIBS to quantify major elements in the sample is quite good proved by the analogous ratio values of $\mathrm{Al}$ and $\mathrm{Si}$ concentrations obtained by the EDX and CF-LIBS techniques.

\section{Conclusions}

In summary, LIBS emission spectra from topaz plasma produced at various laser fluence values showed all the constituents present in the chemical formula viz., $\mathrm{Al}, \mathrm{Si}, \mathrm{O}, \mathrm{F}$ and $\mathrm{H}$. Nitrogen and $\mathrm{Na}$ spectral lines were identified only for the higher fluence value $37.6 \mathrm{~J} \cdot \mathrm{cm}^{-2}$. EDX analysis also verified elemental composition with the exception of $\mathrm{H}, \mathrm{N}$ and $\mathrm{Na}$. Nitrogen lines are expected from ambient air, and the feeble Na line could possibly be from surface contamination. With the help of CF-LIBS analysis, the concentration of major elements, $\mathrm{Al}$ and $\mathrm{Si}$, was estimated to be 60.81 and $39.18 \mathrm{wt} \%$, respectively. At the same time, EDX analysis showed relative concentrations of $\mathrm{Al}, \mathrm{Si}, \mathrm{O}$ and $\mathrm{F}$ as 37.27 , 23.41, 28.94 and $10.38 \mathrm{wt} \%$, respectively. The ratio of relative concentrations of $\mathrm{Al}$ and $\mathrm{Si}$ as measured by CF-LIBS and EDX were found to be 1.55 and 1.59, respectively. This study could be beneficial in understanding the role of impurities in natural topaz and the capability of the LIBS for qualitative and quantitative analyses of gemstones and minerals.

Author Contributions: Conceptualization, S.A.A., M.R., and A.K.; methodology, S.A.A., M.R., N.A. and A.K.; validation, S.A.A., M.R., T.M.K.; formal analysis, S.A.A., M.R., and A.K.; investigation, S.A.A., M.R., and A.K.; resources, S.A.A., M.R., and M.R.I.F.; data curation, A.K.; writing-original draft preparation, S.A.A., and A.K.; writing-review and editing, M.R., T.M.K., P.A., A.S., N.A. and M.U.K.; visualization, P.A., M.U.K.; supervision, M.R. and S.A.A.; project administration, M.R., S.A.A., and M.R.I.F.; funding acquisition, M.R.I.F. All authors have read and agreed to the published version of the manuscript. 
Funding: This work was supported by the Research Universiti Grant, Universiti Kebangsaan Malaysia, Geran Universiti Penyelidikan (GUP), code: 2018-133.

Data Availability Statement: The data generated in this study which is supporting the results presented in this article is available from the corresponding author upon reasonable request.

Acknowledgments: This work was supported by the Research Universiti Grant, Universiti Kebangsaan Malaysia, Geran Universiti Penyelidikan (GUP), code: 2018-133. We are immensely thankful for this funding. We are extremely grateful to Aslam Baig for the provision of a Laboratory facility at the National Centre for Physics, Islamabad, to perform this experiment. We are also appreciative to the National Institute of Laser and Optronics (NILOP), Islamabad, for their help in the EDX analysis.

Conflicts of Interest: The authors declare no conflict of interest.

\section{References}

1. Ulian, G.; Valdrè, G. Effects of fluorine content on the elastic behavior of topaz $\left[\mathrm{Al}_{2} \mathrm{SiO}_{4}(\mathrm{~F}, \mathrm{OH})_{2}\right]$. Am. Min. 2017, 102, 347-356. [CrossRef]

2. Hatipoglu, M.; Babalik, H.; Chamberlain, S.C. Gemstone deposits in Turkey. Rocks Miner. 2010, 85, 124-133. [CrossRef]

3. Rout, P.P.; Sahoo, R.K.; Singh, S.K.; Mishra, B.K. Spectroscopic investigation and colour change of natural topaz exposed to PbO and $\mathrm{CrO}_{3}$ vapour. Vib. Spectrosc. 2017, 88, 1-8. [CrossRef]

4. Salama, S.; Helal, A.I.; Gomaa, M.A.M.; Abou-Salem, L.I.; Nafie, H.; Badawi, E.A. Coloring of Topaz after Irradiation. In Proceedings of the Tenth Radiation Physics \& Protection Conference, Cairo, Egypt, 27-30 November 2010. EG1100453.

5. Souza, D.N.; Lima, J.F.; EG Valerio, M.E.; Caldas, L.V. Performance of pellets and composites of natural colourless topaz as radiation dosemeters. Radiat. Prot. Dosim. 2002, 100, 413-441. [CrossRef]

6. McKeever, S.W.; Chen, C.Y.; Halliburton, L.E. Point defects and the pre-dose effect in natural quartz. Nucl. Tracks Radiat. Meas. 1985, 10, 489-495. [CrossRef]

7. Souza, D.N.; Valerio, M.E.; De-Lima, J.F.; Caldas, L.V. Dosimetric properties of natural Brazilian topaz: A thermally stimulated exoeletronic emission and thermoluminescence study. Nucl. Instrum. Methods Phys. Res. 2000, 166, 209-214. [CrossRef]

8. Souza, D.N.; Meira, R.A.; Lima, J.F.; Valerio, M.E.; Caldas, L.V. Evaluation of doses in radiotherapy using solid-state composites based on natural colourless topaz. Appl. Radiat. Isot. 2003, 58, 489-494. [CrossRef]

9. Sardar, M.; Tufail, M. Thermoluminescent characteristics of topaz from Sabser mine near Sakardu in northern Pakistan. Nucl. Instrum. Methods Phys. Res. 2011, 269, 284-287. [CrossRef]

10. Sardar, M.; Tufail, M. Thermoluminescence and dosimetric aspects of topaz from Yono Shigar mine in Pakistan. J. Lumin. 2012, 132, 1544-1549. [CrossRef]

11. Sardar, M.; Souza, D.N.; Caldas, L.V.; Tufail, M. Effect of visible and ultraviolet light on TL study of topaz glass composites. Scientia Plena 2012, 8, 034801-034809.

12. Miziolek, A.W.; Palleschi, V.; Schechter, I. (Eds.) Laser Induced Breakdown Spectroscopy; Cambridge University Press: Cambridge, UK, 2006.

13. Radziemski, L.; Cremers, D. A brief history of laser-induced breakdown spectroscopy: From the concept of atoms to LIBS 2012. Spectrochim. Acta Part B At. Spec. 2013, 87, 3-10. [CrossRef]

14. Hark, R.R.; Harmon, R.S. Geochemical fingerprinting using LIBS. In Laser-Induced Breakdown Spectroscopy; Springer: Berlin/Heidelberg, Germany, 2014; pp. 309-348.

15. Vadillo, J.M.; Laserna, J.J. Laser-induced breakdown spectroscopy of silicate, vanadate and sulfide rocks. Talanta 1996, 43, 1149-1154. [CrossRef]

16. Harmon, R.S.; Remus, J.; McMillan, N.J.; McManus, C.; Collins, L.; Gottfried, J.L., Jr.; DeLucia, F.C.; Miziolek, A.W. LIBS analysis of geomaterials: Geochemical fingerprinting for the rapid analysis and discrimination of minerals. Appl. Geochem. 2009, 24, 1125-1141. [CrossRef]

17. McMillan, N.J.; Harmon, R.S.; De-Lucia, F.C.; Miziolek, A.M. Laser-induced breakdown spectroscopy analysis of minerals: Carbonates and silicates. Spectrochim. Acta Part B At. Spec. 2007, 62, 1528-1536. [CrossRef]

18. Díaz Pace, D.M.; Gabriele, N.A.; Garcimuño, M.; D'Angelo, C.A.; Bertuccelli, G.; Bertuccelli, D. Analysis of minerals and rocks by laser-induced breakdown spectroscopy. Spec. Lett. 2011, 44, 399-411. [CrossRef]

19. Gottfried, J.L.; Harmon, R.S.; De-Lucia Jr, F.C.; Miziolek, A.W. Multivariate analysis of laser-induced breakdown spectroscopy chemical signatures for geomaterial classification. Spectrochim. Acta Part B At. Spec. 2009, 64, 1009-1019. [CrossRef]

20. Agrosì, G.; Tempesta, G.; Scandale, E.; Legnaioli, S.; Lorenzetti, G.; Pagnotta, S.; Palleschi, V.; Mangone, A.; Lezzerini, M. Application of Laser Induced Breakdown Spectroscopy to the identification of emeralds from different synthetic processes. Spectrochim. Acta Part B At. Spec. 2014, 102, 48-51. [CrossRef]

21. Senesi, G.S. Laser-Induced Breakdown Spectroscopy (LIBS) applied to terrestrial and extraterrestrial analogue geomaterials with emphasis to minerals and rocks. Earth-Sci. Rev. 2014, 139, 231-267. [CrossRef] 
22. Qiao, S.; Ding, Y.; Tian, D.; Yao, L.; Yang, G. A review of laser-induced breakdown spectroscopy for analysis of geological materials. Appl. Spec. Rev. 2015, 50, 1-26. [CrossRef]

23. Sallé, B.; Cremers, D.A.; Maurice, S.; Wiens, R.C. Laser-induced breakdown spectroscopy for space exploration applications: Influence of the ambient pressure on the calibration curves prepared from soil and clay samples. Spectrochim. Acta Part B At. Spec. 2005, 60, 479-490. [CrossRef]

24. Tognoni, E.; Cristoforetti, G.; Legnaioli, S.; Palleschi, V. Calibration-free laser-induced breakdown spectroscopy: State of the art. Spectrochim. Acta Part B At. Spec. 2010, 65, 1-14. [CrossRef]

25. Clegg, S.M.; Sklute, E.; Dyar, M.D.; Barefield, J.E.; Wiens, R.C. Multivariate analysis of remote laser-induced breakdown spectroscopy spectra using partial least squares, principal component analysis, and related techniques. Spectrochim. Acta Part $B$ At. Spec. 2009, 64, 79-88. [CrossRef]

26. Gonzcález, A.; Ortiz, M.; Campos, J. Determination of sulfur content in steel by laser-produced plasma atomic emission spectroscopy. Appl. Spec. 1995, 49, 1632-1635. [CrossRef]

27. Sabsabi, M.; Cielo, P. Quantitative analysis of aluminum alloys by laser-induced breakdown spectroscopy and plasma characterization. Appl. Spec. 1995, 49, 499-507. [CrossRef]

28. De-Giacomo, A.; Dell'Aglio, M.; De Pascale, O.; Longo, S.; Capitelli, M. Laser induced breakdown spectroscopy on meteorites. Spectrochim. Acta Part B At. Spec. 2007, 62, 1606-1611. [CrossRef]

29. Ciucci, A.; Corsi, M.; Palleschi, V.; Rastelli, S.; Salvetti, A.; Tognoni, E. New procedure for quantitative elemental analysis by laser-induced plasma spectroscopy. Appl. Spec. 1999, 53, 960-964. [CrossRef]

30. Sirven, J.B.; Bousquet, B.; Canioni, L.; Sarger, L.; Tellier, S.; Potin-Gautier, M.; Le Hecho, I. Qualitative and quantitative investigation of chromium-polluted soils by laser-induced breakdown spectroscopy combined with neural networks analysis. Anal. Bioanal. Chem. 2006, 385, 256-262. [CrossRef]

31. De-Giacomo, A.; Dell'Aglio, M.; Gaudiuso, R.; Santagata, A.; Senesi, G.S.; Rossi, M.; Ghiara, M.R.; Capitelli, F.; De-Pascale, O. A laser induced breakdown spectroscopy application based on local thermodynamic equilibrium assumption for the elemental analysis of alexandrite gemstone and copper-based alloys. J. Chem. Phys. 2012, 398, 233-238. [CrossRef]

32. Hafeez, M.; Abbasi, S.A.; Rafique, M.; Hayder, R.; Sajid, M.; Iqbal, J.; Ahmad, N.; Shahida, S. Calibration-free laser-induced breakdown spectroscopic analysis of copper-rich mineral collected from the Gilgit-Baltistan region of Pakistan. Appl. Opt. 2020, 59, 68-76. [CrossRef] [PubMed]

33. Ahmad, N.; Ahmed, R.; Umar, Z.A.; Liaqat, U.; Manzoor, U.; Baig, M.A. Qualitative and quantitative analyses of copper ores collected from Baluchistan, Pakistan using LIBS and LA-TOF-MS. Appl. Phys. B 2018, 124, 160. [CrossRef]

34. Rossi, M.; Dell'Aglio, M.; De-Giacomo, A.; Gaudiuso, R.; Senesi, G.S.; De-Pascale, O.; Capitelli, F.; Nestola, F.; Ghiara, M.R. Multi-methodological investigation of kunzite, hiddenite, alexandrite, elbaite and topaz, based on laser-induced breakdown spectroscopy and conventional analytical techniques for supporting mineralogical characterization. Phys. Chem. Miner. 2014, 41, 127-140. [CrossRef]

35. Alvarez-Llamas, C.; Pisonero, J.; Bordel, N. Quantification of fluorine traces in solid samples using CaF molecular emission bands in atmospheric air Laser-Induced Breakdown Spectroscopy. Spectrochim. Acta Part B At. Spec. 2016, 123, 157-162. [CrossRef]

36. Pořízka, P.; Kaski, S.; Hrdlička, A.; Modlitbová, P.; Sládková, L.; Häkkänen, H.; Prochazka, D.; Novotný, J.; Gadas, P.; Čelko, L.; et al. Detection of fluorine using laser-induced breakdown spectroscopy and Raman spectroscopy. J. Anal. Atom. Spectrom. 2017, 32, 1966-1974. [CrossRef]

37. Quarles, C.D.; Gonzalez, J.J.; East, L.J.; Yoo, J.H.; Morey, M.; Russo, R.E. Fluorine analysis using laser induced breakdown spectroscopy (LIBS). J. Anal. Atom. Spectrom. 2014, 29, 1238-1242. [CrossRef]

38. Foucaud, Y.; Fabre, C.; Demeusy, B.; Filippova, I.V.; Filippov, L.O. Optimisation of fast quantification of fluorine content using handheld laser induced breakdown spectroscopy. Spectrochim. Acta Part B At. Spec. 2019, 158, 105628. [CrossRef]

39. Agheem, M.H.; Shah, M.T.; Khan, T.U. Gems and Gem-Bearing Pegmatites of the Shigsr Valley, Skardu, Norhtern Pakistan. JHES 2004, 37, 167-178.

40. Searle, M.P.; Tirrul, R. Structural and thermal evolution of the Karakoram crust. J. Geol. Soc. 1991, 148, 65-82. [CrossRef]

41. Fraser, J.E.; Searle, M.P.; Parrish, R.R.; Noble, S.R. Chronology of deformation, metamorphism, and magmatism in the southern Karakoram Mountains. Geol. Soc. Am. Bull. 2001, 113, 1443-1455. [CrossRef]

42. Ahmed, N.; Ahmed, R.; Baig, M.A. Analytical analysis of different karats of gold using laser induced breakdown spectroscopy (LIBS) and laser ablation time of flight mass spectrometer (LA-TOF-MS). Plasma Chem. Plasma Process. 2018, 38, $207-222$. [CrossRef]

43. Aguilera, J.A.; Aragon, C. A comparison of the temperatures and electron densities of laser-produced plasmas obtained in air, argon, and helium at atmospheric pressure. Appl. Phys. A. 1999, 69, S475-S478. [CrossRef]

44. Cristoforetti, G.; De-Giacomo, A.; Dell'Aglio, M.; Legnaioli, S.; Tognoni, E.; Palleschi, V.; Omenetto, N. Local thermodynamic equilibrium in laser-induced breakdown spectroscopy: Beyond the McWhirter criterion. Spectrochim. Acta Part B At. Spec. 2010, 65, 86-95. [CrossRef]

45. Gigosos, M.A.; González, M.A.; Cardenoso, V. Computer simulated Balmer-alpha,-beta and-gamma Stark line profiles for non-equilibrium plasmas diagnostics. Spectrochim. Acta Part B At. Spec. 2003, 58, 1489-1504. [CrossRef]

46. Chan, W.T.; Russo, R.E. Study of laser-material interactions using inductively coupled plasma-atomic emission spectrometry. Spectrochim. Acta Part B At. Spec. 1991, 46, 1471-1486. [CrossRef] 
47. Capitelli, M.; Casavola, A.; Colonna, G.; De-Giacomo, A. Laser-induced plasma expansion: Theoretical and experimental aspects. Spectrochim. Acta Part B At. Spec. 2004, 59, 271-289. [CrossRef]

48. National Institute Of Standards and Technology. NIST Atomic Spectra Database Lines Form. Available online: https://physics. nist.gov/PhysRefData/ASD/lines_form.html (accessed on 8 September 2020).

49. Ahmed, N.; Farooq, K.; Shahida, S.; ul Haq, K.; Abbasi, S.A.; Umar, Z.A.; Ahmed, R.; Baig, M.A. Spectrochemical analysis of Pakistani bakery breads using laser induced breakdown spectroscopy. Optik 2021, 226, 165743. [CrossRef]

50. Thompson, J.R.; Wiens, R.C.; Barefield, J.E.; Vaniman, D.T.; Newsom, H.E.; Clegg, S.M. Remote laser-induced breakdown spectroscopy analyses of Dar al Gani 476 and Zagami Martian meteorites. J. Geophys. Res. Planets 2006, 111, E5. [CrossRef]

51. Sun, L.; Yu, H. Correction of self-absorption effect in calibration-free laser-induced breakdown spectroscopy by an internal reference method. Talanta 2009, 79, 388-395. [CrossRef] [PubMed]

52. Colon, C.; Hatem, G.; Verdugo, E.; Ruiz, P.; Campos, J. Measurement of the Stark broadening and shift parameters for several ultraviolet lines of singly ionized aluminum. J. Appl. Phys. 1993, 73, 4752-4758. [CrossRef]

53. Stark Broadening Parameters for Neutral and Singly Charged Ions: Helium through Calcium and Cesium. Available online: https:/ / griem.obspm.fr/ (accessed on 9 September 2020).

54. Shaikh, N.M.; Hafeez, S.; Rashid, B.; Baig, M.A. Spectroscopic studies of laser induced aluminum plasma using fundamental, second and third harmonics of a Nd: YAG laser. Eur. Phys. J. D 2007, 44, 371-379. [CrossRef]

55. Mineralogy Database. Available online: http:/ / webmineral.com/data/Topaz.shtml\#.X4idTtUzbIU (accessed on 16 October 2020).

56. Souza, D.N.; De-Lima, J.F.; Valerio, M.E. Thermoluminescence of natural topaz crystals of differing genesis. In Materials Science Forum; Trans Tech Publications Ltd.: Stafa-Zurich, Switzerland, 1997; Volume 239, pp. 765-768. 